\title{
БАЛАНСИРОВАНИЕ ФОРМЫ ОПЛАТЫ ТРУДА ДЛЯ МАКСИМАЛЬНО ЭФФЕКТИВНОГО УПРАВЛЕНИЯ ПРЕДПРИЯТИЕМ
}

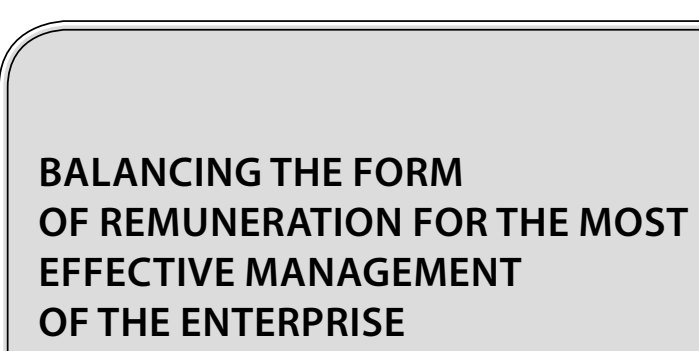

T. Bakiyev

Summary. In modern conditions, the choice of forms of remuneration for employees is of great importance, since it directly affects the efficiency of their work and the efficiency of the entire enterprise. While the use of piecework and time-based forms of remuneration, it is important to adopt a balancing act, because the main goal of every business enterprise, which is profit and increase efficiency. This, in turn, is achieved by managing it as efficiently as possible.

The article examines the forms of remuneration, the main of which are piecework and time-based, identifies their advantages and disadvantages in various conditions. The author substantiates the necessity of simultaneous use of both forms of remuneration for employees of the same specialization, as well as the importance of balancing them in order to improve the efficiency of the enterprise. Using the example of employees of the main production shop, the author proves the effectiveness of the developed management method by finding a balance in the number of employees of one specialization who have piecework and time-based wages. The use of this method allows you to reduce the total salary fund and increase labor productivity, which has a positive effect on the efficiency of the enterprise.

Keywords: remuneration of labor, forms of remuneration of labor, piecerate remuneration of labor, time remuneration of labor, the balancing of forms of remuneration, the effectiveness of forms of remuneration.

\author{
Бакиев Тимур \\ Heriot Watt University, Единбург, Шотландия, \\ Великобритания \\ tbakiyev@hotmail.com
}

Аннотация. В современных условиях выбор форм оплаты труда работников имеет немаловажное значение, поскольку напрямую влияет на эффективность их труда и эффективность деятельности всего предприятия. При одновременном применении сдельной и повременной форм оплаты труда важно их грамотное балансирование, что обусловлено главной целью каждого коммерческого предприятия, которой является получение прибыли и повышение эффективности деятельности. Это, в свою очередь, достигается максимально эффективным управлением им.

В статье рассматриваются формы оплаты труда, основными из которых являются сдельная и повременная, выявляются их достоинства и недостатки в различных условиях. Автором обосновывается необходимость одновременного использования обеих форм оплаты труда для работников одной специализации, а также важность их балансирования в целях повышения эффективности деятельности предприятия. На примере работников цеха основного производства автором доказана эффективность разработанного метода управления путем нахождения баланса по количеству работников одной специализации, имеющих сдельную и повременную оплату труда. Применение данного метода позволяет снижать общий фонд оплаты и повышать производительность труда, что положительно сказывается на эффективности деятельности предприятия.

Ключевые слова: оплата труда, формы оплаты труда, сдельная оплата труда, повременная оплата труда, балансирование форм оплаты труда, эффективность форм оплаты труда.
3 аработная плата в современных экономических условиях является важнейшим аспектом, оказывающим влияние на эффективность деятельности субъектов хозяйствования в целом. Для эффективной деятельности предприятий, независимо от формы собственности, одним из основополагающих аспектов является оптимальная организация системы оплаты труда [4, c. 40].
Трудовой кодекс РФ определяет заработную плату в качестве вознаграждения за труд, размер которого обусловлен множеством факторов и включает помимо базовой части компенсационные и стимулирующие выплаты [1]. При этом на законодательном уровне предоставляется свобода выбора форм оплаты труда на каждом предприятии в зависимости от условий деятельности и других факторов. 
Обзор литературных источников $[3,5,6,7,8]$ показал, что заработная плата рассматривается с двух точек зрения: с точки зрения работника и с точки зрения работодателя. При этом данные подходы имеют разные цели, поэтому по-разному, прямо или косвенно, регулируют размер заработной платы.

Обобщая представленные в литературе определения, по нашему мнению, с точки зрения экономического субъекта (предприятия) заработная плата представляет собой цену трудовых ресурсов, которые участвуют в производстве и другой деятельности предприятия. Для работника заработная плата представляет собой определенное вознаграждение за трудовую деятельность, регулируемое законодательством и оформленное в соответствующих документах, размер которого напрямую зависит от квалификации сотрудника и имеющихся условий трудовой деятельности.

Несмотря на то, что в последнее время большое распространение получили новые современные формы оплаты труда (грейдирование персонала, бестарифная система оплаты труда, пропорциональная система и другие [6]), на крупных российских предприятиях традиционно применяются две основные формы оплаты труда: сдельная и повременная. Условия их применения зависят от многих факторов, например, специфических особенностей трудовых обязанностей, технической оснащенности процесса производства и других $[6,8]$.

При повременной форме оплаты труда рабочий получает оклад за фактически отработанное время, на основе часовой или дневной ставки [8, с. 248]. При сдельной оплате труда заработок зависит от способностей работника и объема выполненной им работы.

Как показывают исследования экономистов, уровень производительности труда работников при использовании сдельной формы оплаты превышает аналогичный показатель при повременной форме. Например, внедрение сдельной оплаты труда на предприятиях обувной или швейной промышленности позволило поднять уровень заработной платы рабочих на 14-16\% в сравнении с повременной формой, тогда как аналогичный показатель в автомобильной промышленности выше на $20-50 \%$ [10].

Однако сдельная оплата труда не всегда дает положительный результат. К ее недостаткам относятся трудности с учетом таких факторов, как технические неисправности оборудования, болезни работника, уровень качества продукции, отсутствие групповой мотивации, недовольство сотрудников установленными нормами или их изменениями. В свою очередь, к недостаткам повременной формы оплаты труда относят отсутствие воз- можности увеличения выпуска продукции, повышения производительности труда, низкая мотивация к производительному труду, необходимость дополнительного контроля и стимулирования труда работников со стороны и другое $[9,10]$.

Поэтому важно учитывать множество факторов, влияющих на производительность труда работников в зависимости от той или иной формы оплаты. Уровень производительности труда и его оплаты представляют собой важные социально-экономические критерии, показывающие эффективность производственного процесса. Поэтому отслеживание зависимости этих показателей достаточно важно осуществлять в целях обеспечения устойчивости каждого предприятия [5, с. 23].

Повышения эффективности деятельности можно добиться в данном случае двумя способами: снижение расходов на оплату труда или повышение производительности труда (выработки продукции) [2, 7]. Для этих целей предлагается одновременное применение повременной и сдельной форм оплаты труда работников одной специализации, для чего используется метод балансирования форм оплаты труда.

Рассмотрим данную разработку на примере рабочих основного цеха предприятия, занимающегося производством оборудования для нефтесервисной компании. В основном цехе предприятия применяется, как сдельная, так и повременная формы оплата труда. Оплата труда рабочих при повременной форме состоит из установленного оклада и премии $100 \%$. При этом премия может быть снижена за невыполнение плана (нормированного задания). Сдельная форма оплаты труда работников основного цеха заключается в том, что работник получает заработную плату, исходя из выполненного количества деталей, а также премию 100\%.

В силу стимулирующей формы оплаты труда сдельщики стараются выполнить больше деталей, чем предусмотрено нормированным заданием, прежде всего, с целью получения большей заработной платы. Кроме того, это обусловлено также некоторыми благоприятными факторами, например, в виде улучшения технологического процесса, внедрения новых вспомогательных инструментов и других. В результате перевыполнения плана, например, при 120\% плана, руководством предприятия принимается решение о снижении нормо-часов на изготовление одной детали, например, увеличивая нормированное задание с 10 до 11 деталей в сутки в условиях выполнения сдельщиками 12 деталей (выполнение $120 \%$ плана). Это позволяет повысить эффективность труда (выработку продукции за определенный промежуток времени), а также сократить фонд оплаты труда. Следовательно, по выработке сдельщиков руко- 
Таблица 1. Фактическая оплата труда работников основного цеха в месяц

\begin{tabular}{|c|c|c|c|c|c|c|}
\hline \multirow[b]{2}{*}{ Показатель } & \multicolumn{2}{|c|}{ 100\% выполнения плана } & \multicolumn{2}{|c|}{ 110\% выполнения плана } & \multicolumn{2}{|c|}{ 120\% выполнения плана } \\
\hline & $\begin{array}{l}\text { Повремен- } \\
\text { щики }\end{array}$ & Сдельщики & $\begin{array}{l}\text { Повремен- } \\
\text { щики }\end{array}$ & Сдельщики & $\begin{array}{l}\text { Повремен- } \\
\text { щики }\end{array}$ & Сдельщики \\
\hline Оклад, тыс. руб. & 25 & 25 & 25 & 27,5 & 25 & 30 \\
\hline Премия (100\%), тыс. руб. & 25 & 25 & 25 & 27,5 & 25 & 30 \\
\hline Итого, тыс. руб. & 50 & 50 & 50 & 55 & 50 & 60 \\
\hline
\end{tabular}

Таблица 2. Изменение нормированного задания в результате превышения плана рабочими-сдельщиками

\begin{tabular}{|c|c|c|c|c|c|c|c|c|}
\hline \multirow[b]{2}{*}{ Показатель } & \multicolumn{2}{|l|}{1 месяц } & \multicolumn{2}{|l|}{2 месяц } & \multicolumn{2}{|l|}{3 месяц } & \multicolumn{2}{|l|}{4 месяц } \\
\hline & $\begin{array}{l}\text { Повремен- } \\
\text { щики }\end{array}$ & Сдельщики & $\begin{array}{l}\text { Повремен- } \\
\text { щики }\end{array}$ & $\begin{array}{l}\text { Сдельщи- } \\
\text { ки }\end{array}$ & $\begin{array}{l}\text { Повремен- } \\
\text { щики }\end{array}$ & $\begin{array}{l}\text { Сдельщи- } \\
\text { ки }\end{array}$ & $\begin{array}{l}\text { Повремен- } \\
\text { щики }\end{array}$ & $\begin{array}{l}\text { Сдельщи- } \\
\text { ки }\end{array}$ \\
\hline $\begin{array}{l}\text { Среднемесячная } \\
\text { выработка, тыс. шт. }\end{array}$ & 10 & 12 & 11 & 12 & 12 & 12 & 12 & 13 \\
\hline $\begin{array}{l}\text { Норма оплаты, } \\
\text { исходя из оклада, тыс. } \\
\text { руб. }\end{array}$ & 2,5 & 2,5 & 2,27 & 2,27 & 2,08 & 2,08 & 2,08 & 2,08 \\
\hline $\begin{array}{l}\text { ФОТ одного } \\
\text { работника, тыс.руб. }\end{array}$ & 25 & 30 & 25 & 27 & 25 & 25 & 25 & 27 \\
\hline $\begin{array}{l}\text { Дополнительная } \\
\text { оплата } \\
\text { за перевыполнение } \\
\text { плана, тыс.руб. }\end{array}$ & - & +5 & - & +2 & - & 0 & - & +2 \\
\hline
\end{tabular}

Таблица 3. Возможные варианты численности рабочих-сдельщиков и рабочих-повременщиков, а также сумма дополнительной оплаты сдельщикам за превышение плана

\begin{tabular}{|c|c|c|c|}
\hline \multicolumn{2}{|c|}{ Возможный вариант } & $\begin{array}{l}\text { Количество ра- } \\
\text { ботников, чел. }\end{array}$ & $\begin{array}{l}\text { Дополнительные расходы на оплату сдельщикам } \\
\text { за перевыполнение плана, тыс. руб. }\end{array}$ \\
\hline \multirow{3}{*}{1} & Сдельщики & 0 & 0 \\
\hline & Повременщики & 200 & - \\
\hline & Итого & 200 & - \\
\hline \multirow{3}{*}{2} & Сдельщики & 20 & 180 \\
\hline & Повременщики & 180 & - \\
\hline & Итого & 200 & - \\
\hline \multirow{3}{*}{3} & Сдельщики & 40 & 360 \\
\hline & Повременщики & 160 & - \\
\hline & Итого & 200 & - \\
\hline \multirow{3}{*}{4} & Сдельщики & 60 & 540 \\
\hline & Повременщики & 140 & - \\
\hline & Итого & 200 & - \\
\hline \multirow{3}{*}{5} & Сдельщики & 70 & 630 \\
\hline & Повременщики & 120 & - \\
\hline & Итого & 200 & - \\
\hline
\end{tabular}


водство видит возможности повышения эффективности труда в различных условиях. Особенно это важно при запуске производства новых деталей, выпуск которых нормирован не достаточно хорошо, что требует эффективного регулирования со стороны руководителей.

Однако одновременное использование повременной оплаты труда со сдельной также приносит положительные результаты. Прежде всего, по причине того, что перевод всех работников на сдельную форму оплаты труда экономически не выгоден предприятию, так как при постоянном перевыполнении плана увеличиваются общие расходы на оплату труда всех работников. Тогда как применение повременной формы оплаты ограничивает ее в рамках оклада. Вместе с тем, необходимо отметить также возможность снижения фонда оплаты труда (в части премии) в результате невыполнения нормированного задания работниками-повременщиками, что также снижает расходы на оплату труда.

Следовательно, одновременное применение сдельной и повременной форм оплаты труда для работников одной специализации может быть экономически выгодным для предприятия. Однако руководитель должен знать, при каком соотношении количества работников обеих форм оплаты труда будет достигаться наибольшая эффективность. В данном случае эффективность можно оценить, сравнивая сумму дополнительных расходов на оплату труда сдельщиков с суммой прироста производительности труда. Фактический заработок рабочих обеих форм оплаты труда на исследуемом предприятии представлен в таблице 1.

Как можно отметить, если не снижать нормо-часы на изготовление деталей и не увеличивать нормированное задание, рабочие-сдельщики будут постоянно перевыполнять план, что увеличивает расходы на оплату труда работников предприятия.

Для выявления оптимального количества работников-сдельщиков основного цеха необходимо сравнить сумму дополнительной заработной платы, выплачиваемую сдельщикам за превышение плана, и сумму прироста производительности труда в результате увеличения выработки при условии снижения норм и увеличения нормированного задания.

Рассматривая период 4 месяца, за который рабочими-сдельщиками были показаны разные результаты (100-120\%\% выполнения плана), а также было осуществлено снижение норм и увеличение нормированного задания с 10 до 12 тыс. деталей, был установлен рост производительности труда одного рабочего основного цеха (как частное от деления выручки от продаж на численность рабочих) с 2925 тыс. руб. до 3510 тыс. руб., то есть на 585 тыс. руб.
Вместе с тем, за данный период было рассчитано, что на 1 рабочего-сдельщика приходится 9 тыс. руб. расходов на дополнительную оплату за перевыполнение плана (таблица 2).

Следовательно, сумму дополнительно вовлеченного фонда оплаты труда всех рабочих-сдельщиков можно определить как произведение данного показателя на 1 работника и необходимого количества работников. Соответственно, в таблице 3 представлены возможные варианты численности рабочих-сдельщиков и рабочих-повременщиков, а также общая сумма дополнительной оплаты сдельщикам за превышение плана.

Расчеты показали, что в данном случае количество рабочих-сдельщиков не должно превышать 60 человек из 200 рабочих основного цеха, так как в противном случае дополнительные расходы на оплату за перевыполнение плана сдельщиками будут больше суммы прироста производительности труда рабочих (585 тыс. руб.). Следовательно, для целей эффективности работы предприятия количество рабочих-сдельщиков основного цеха на исследуемом предприятии не должно превышать 30\% при заданных условиях.

Таким образом, одновременное применение сдельной и повременной форм оплаты труда для работников одной специализации благоприятно сказывается на результатах деятельности всего предприятия. Сдельная оплата труда позволяет повысить производительность труда работников (увеличение выработки продукции), тогда как повременная оплата труда выявляет резервы сокращения фонда заработной платы, то есть расходов предприятия. Несмотря на указанную эффективность применения обеих форм оплаты труда для работников одной специализации, сложность использования данной разработки заключается в необходимости осуществления постоянного балансирования форм оплаты для достижения максимальной эффективности управления предприятием. На это оказывает влияние множество факторов, таких как количество рассматриваемых работников, размер оклада, специфика производственного процесса, наличие тенденции к перевыполнению плановых заданий и другое. Поэтому данный вопрос должен решаться индивидуально на каждом предприятии. В частности, В рассмотренном примере было рассчитано, что количество рабочих-сдельщиков не должно превышать 60 человек из 200 рабочих основного цеха (30\% от численности). В этом случае дополнительные расходы на оплату за перевыполнение плана сдельщиками будут меньше суммы прироста производительности труда рабочих, что гарантирует повышение эффективности работы предприятия при заданных условиях. 


\section{ЛИТЕРАТУРА}

1. Трудовой кодекс РФ.—- М.: КНОРУС, 2021.- 206 с.

2. Валькович, 0.Н., Соколова Т.Э. Современные подходы к построению системы оплаты труда персонала // Символ науки.— 2017.— № 7.— C. 28-31.

3. Горелов, Н.А. Оплата труда персонала: методология и расчеты / Н.А. Горелов. — М.: Юрайт, 2017. - 412 c.

4. Григорьева, И.В., Хабазина Л.Н. Алгоритм формирования системы оплаты труда работников организации по результатам их труда // Вестник Российского университета кооперации. - 2019.— № 2.- С. 40-47.

5. Давлетов, А.Р. Понятие и роль производительности труда в организации, ее взаимосвязь с оплатой труда // Наука без границ. — 2020.— № 9.— C. 22-27.

6. Камалова, Д.А. Изменения в практике оплаты труда на производстве // Международный научно-исследовательский журнал. — 2019.— № 10 (88). C. 67-69.

7. Костенькова, Т.А. Управление системой оплаты труда на промышленных предприятиях // Экономика труда. — 2019.— № 1.— С. 495-502.

8. Чернявская, С.А., Папова Л.В. Отдельные аспекты организации оплаты труда // Вестник Академии знаний. — 2019. — № 35. — С. $248-253$.

9. Вальчук, В. Сдельная оплата — враг № 1 повышения производительности [Электронный ресурс] // Тосреорle.com. — Peжим доступа: https://tocреople. com/2019/12/sdelnaya-oplata-vrag-n1-povysheniya-proizvoditelnosti/ (дата обращения: 27.01.2021).

10. Сдельная и повременная форма оплаты труда: преимущества и недостатки [Электронный ресурс] // Клерк.ру.— Режим доступа: https://www.klerk.ru/ job/articles/436793/ (дата обращения: 27.01.2021).

(c) Бакиев Тимур ( tbakiyev@hotmail.com ).

Журнал «Современная наука: актуальные проблемы теории и практики»

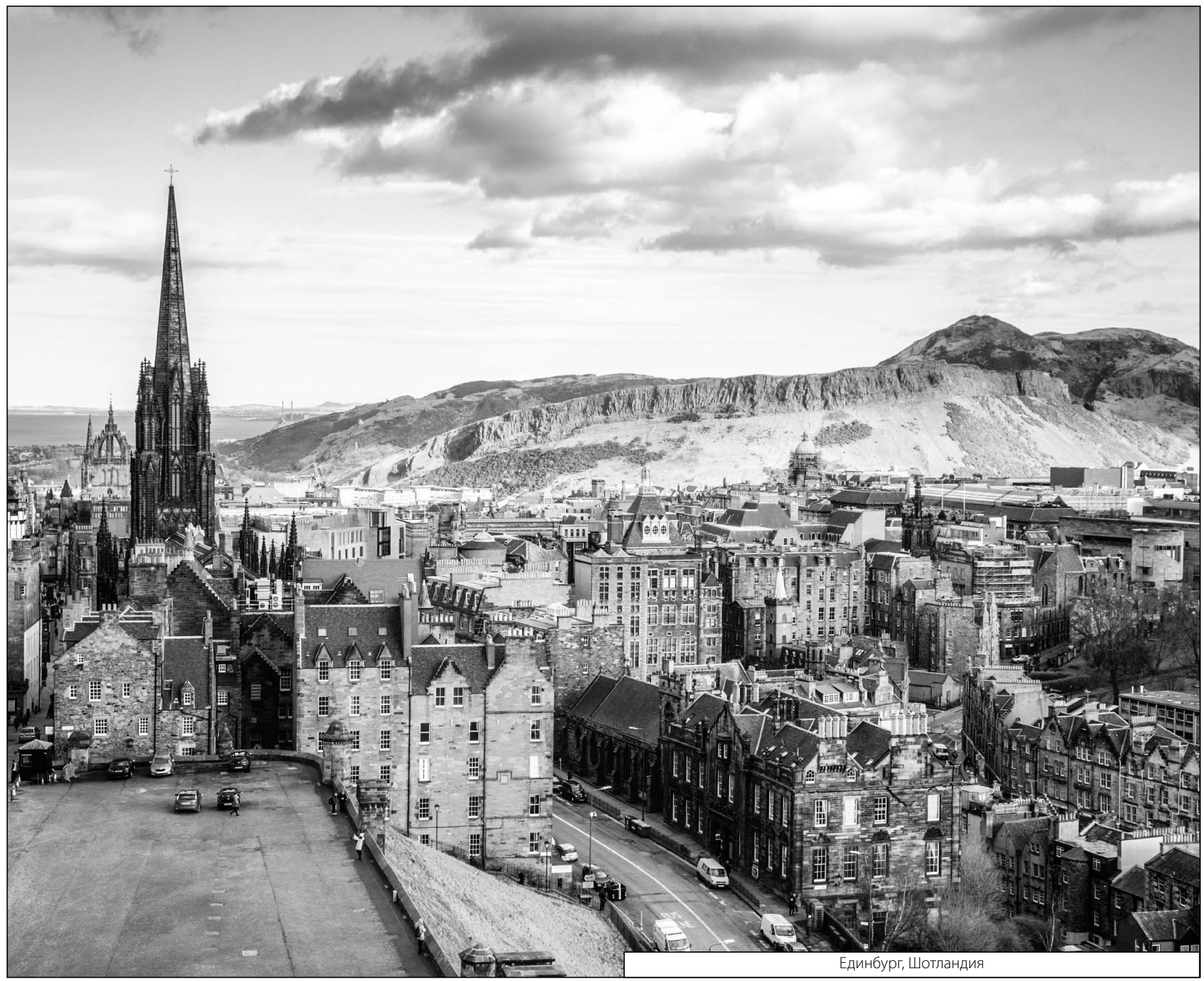

